\title{
Correction to: A multiplex marker set for microsatellite typing and sexing of sooty terns Onychoprion fuscatus
}

Lucy J. H. Garrett ${ }^{1,2^{*}}$, Deborah A. Dawson², Gavin J. Horsburgh ${ }^{2}$ and S. James Reynolds ${ }^{1,3}$

\section{Correction to: BMC Res Notes (2017) 10:756}

https://doi.org/10.1186/s13104-017-3084-9

Following publication of the original article [1], one of the authors reported that his name was listed incorrectly, and that he would like his name to appear as S. James Reynolds instead of Silas James Reynolds. The latter format would confuse citations as all his previous publications are in the former format.

The original article has been updated.

\section{Author details}

${ }^{1}$ Centre for Ornithology, School of Biosciences, College of Life \& Environmental Sciences, University of Birmingham, Edgbaston, Birmingham B15 $2 T T$, UK. ${ }^{2}$ Department of Animal and Plant Sciences, University of Sheffield, Sheffield S10 2TN, UK. ${ }^{3}$ Army Ornithological Society (AOS), c/o Prince Consort Library, Knollys Road, Aldershot, Hampshire GU11 1PS, UK.

The original article can be found online at https://doi.org/10.1186/ s13104-017-3084-9.

\section{Publisher's Note}

Springer Nature remains neutral with regard to jurisdictional claims in published maps and institutional affiliations.

Received: 18 January 2018 Accepted: 18 January 2018

Published online: 31 January 2018

\section{Reference}

1. Garrett LJH, Dawson DA, Horsburgh GJ, Reynolds SJ. A multiplex marker set for microsatellite typing and sexing of sooty terns Onychoprion fuscatus. BMC Res Notes. 2017;10:756. https://doi.org/10.1186/ s13104-017-3084-9.

*Correspondence: LG478@bham.ac.uk

${ }^{1}$ Centre for Ornithology, School of Biosciences, College of Life \&

Environmental Sciences, University of Birmingham, Edgbaston,

Birmingham B15 2TT, UK

Full list of author information is available at the end of the article 